\title{
OS IMPACTOS AMBIENTAIS DA IIRSA-COSIPLAN NO ARCO CENTRAL DA FRONTEIRA BRASILEIRA
}

\author{
Camilo Pereira Carneiro' \\ pereiracarneiro.camilo@gmail.com \\ Felipe Pereira Matoso ${ }^{2}$ \\ matoso.felipe@yahoo.com.br \\ Katiucy Santos ${ }^{3}$ \\ katiucy.santos@outlook.com
}

\begin{abstract}
Resumo: O processo de integração sul-ame- Abstract: The South American integration ricano, que teve início no final do século $X X$, process began at the end of the 20th century. possibilitou a emergência de iniciativas de The main initiatives of approximation between aproximação entre os países do subcontinen- the countries of the subcontinent were MERte, com destaque para o MERCOSUL, a UNA- COSUR, UNASUR and IIRSA-COSIPLAN. SUL e a IIRSA-COSIPLAN. Esta última gerou This last initiative had a great impact materiaum importante impacto, materializado de modo lized especially in border areas. Critics of the especial em zonas de fronteira. Após quase IIRSA-COSIPLAN claim that infrastructure produas décadas de sua criação, críticos à inicia- jects are characterized by the lack of participativa alegam que os projetos de infraestrutura tion of communities in the areas where works implementados caracterizam-se pela falta de are carried out. The lack of observance of soparticipação das comunidades locais. A inob- cio-environmental aspects results in a series of servância dos aspectos socioambientais quan- negative impacts in the environmental, social, do da execução das obras, tem efeitos negati- economic and cultural spheres. The present vos nas esferas ambiental, social, econômica e paper will present an analysis from the perscultural. O presente trabalho trará uma análise pective of International Relations of the socioa partir das Relações Internacionais sobre os -environmental impacts of IIRSA-COSIPLAN in impactos socioambientais da IIRSA-COSI- the Central Arc of the Brazilian border. This is a PLAN no Arco Central da fronteira brasileira. qualitative research, based on a bibliographical Trata-se de uma pesquisa qualitativa, pautada analysis.
\end{abstract}

em análise bibliográfica.

Keywords: IIRSA-COSIPLAN, environPalavras-chave: IIRSA-COSIPLAN; impac- mental impacts; Central arch; border. tos socioambientais; Arco Central; fronteira.

1 Doutor em Geografia. Professor Visitante do Programa de Pós-Graduação em Fronteiras e Direitos Humanos da UFGD.

2 Mestrando do Programa de Pós-Graduação em Fronteiras e Direitos Humanos da UFGD. Especialista em Direitos Difusos e Coletivos pela UEMS.

3 Mestranda do Programa de Pós-Graduação em Fronteiras e Direitos Humanos da UFGD. 


\section{0}

\section{INTRODUÇÃO}

Criada no ano 2000, a IIRSA - Iniciativa para Infraestrutura Regional Sul-Americana - configura uma das principais políticas de integração do subcontinente. A iniciativa foi incorporada pela UNASUL - União de Nações Sul-Americanas - em 2008, passando posteriormente a integrar o Conselho Sul-Americano de Infraestrutura e Planejamento (COSIPLAN) em 2011. Constituída originalmente como uma estratégia em prol do desenvolvimento das infraestruturas de transporte, energia e comunicações na América do Sul, a iniciativa abarca uma carteira com 581 projetos, ordenada ao longo de dez Eixos de Integração e Desenvolvimento - EID (COSIPLAN, 2017).

Os principais eixos da IIRSA-COSIPLAN que abrangem o Arco Central da fronteira brasileira ${ }^{4}$ são: Capricórnio, Hidrovia Paraguai-Paraná e Interoceânico Central. Estes eixos contemplam projetos que originam impactos ambientais e sociais justificados pelo ideal da integração regional.

Os referidos projetos têm provocado grandes transformações em zonas de fronteira, áreas que historicamente convivem com problemas como baixa densidade populacional, carência de infraestruturas, além da distância dos centros decisórios nacionais e que têm a realidade agravada pela ausência de iniciativas políticas que contemplem as necessidades das populações locais.

Os problemas mencionados refletem diretamente nas áreas de saúde, educação, segurança e meio ambiente. Nesse sentido, a questão ambiental merece destaque, visto que o manejo adequado dos recursos e a proteção ambiental são fundamentais para a sobrevivência de comunidades residentes na faixa de fronteira. Dessa maneira, o presente trabalho se justifica principalmente pela necessidade de se pensar as questões ambientais para a implementação de projetos de infraestrutura voltados para a integração regional, uma vez que os custos dessas obras, financiadas principalmente por um grupo de grandes empresas privadas, inicialmente apoiadas pelo BNDES (principal protagonista da IIRSA-COSIPLAN até 2014), e posteriormente por entidades como BID, CAF e FONPLATA, refletem em irreversíveis danos às populações e ao meio ambiente envolvidos neste processo.

O trabalho visa também preencher uma lacuna existente acerca do tema, haja vista a baixa divulgação da IIRSA-COSIPLAN na mídia e a escassa informação sobre a iniciativa disponibilizada em órgãos governamentais e ministérios. Trata-se de uma pesquisa qualitativa, a partir da ótica das Relações Internacionais, pautada em análise bibliográfica, que tem como recorte temporal o período entre os anos 2000 e 2018.

4 O Ministério da Integração Nacional (MIN) divide a faixa de fronteira em três grandes arcos: Norte, Central e Sul. O arco Central abrange as faixas de fronteira dos estados de Mato Grosso, Mato Grosso do Sul e Rondônia. 


\section{1}

Inicialmente, será apresentado o lócus de análise em questão - o Arco Central da fronteira brasileira - bem como os reflexos dos principais projetos de integração que o caracteriza, de modo a analisar em que medida os projetos da IIRSA-COSIPLAN cumprem sua finalidade primordial, a integração regional sul-americana. Na sequência, será salientada a importância da participação da população local nas discussões concernentes aos projetos da IIRSA-COSIPLAN. Por fim, o trabalho abordará ainda a questão da viabilidade ambiental dos projetos de infraestrutura da iniciativa, trazendo uma análise dos aspectos econômicos, políticos, sociais e ambientais que envolvem o ideal de integração regional da IIRSA-COSIPLAN.

\section{O ARCO CENTRAL DA FRONTEIRA BRASILEIRA E OS IM- PACTOS DO PROCESSO DE INTEGRAÇÃO SUL-AMERICANO}

Embora reconhecida como área estratégica para a integração sul-americana, tendo em vista representar aproximadamente $27 \%$ do território nacional e fazer divisa com dez países, a faixa de fronteira do Brasil é caracterizada pela dificuldade de acesso a serviços públicos, escassez de investimentos, além de ser pouco desenvolvida economicamente.

A partir de 2007, a Política Nacional de Desenvolvimento Regional ${ }^{5}$, por meio do fortalecimento e estímulo de novos eixos dinâmicos da economia passou a dar maior atenção à população fronteiriça, constituindo uma agenda positiva de desenvolvimento baseada na integração e sustentabilidade, articulando parcerias no intuito de não só inserir e integrar as sociedades locais como integrar os países vizinhos, com objetivo de alocar o uso dos recursos públicos na busca do desenvolvimento regional (MIN, 2011).

Com o advento do regionalismo, no final do século $X X$ e o surgimento de blocos regionais como o MERCOSUL, houve alteração do enfoque nas questões de segurança nas zonas de fronteira para um novo enfoque institucional civil/ ambiental. Esta mudança resultou na necessidade de investir esforços para a construção de um novo cenário nas zonas de fronteira em prol do desenvolvimento regional.

No tocante à realidade brasileira, a faixa de fronteira é gerida de acordo com a Lei n. 6.634 de 2 de maio de 1979, com o Decreto n. 85.064/80 e o artigo $20, \S 2^{\circ}$ da Constituição Federal de $1988^{\circ}$. Esta legislação estabelece uma série de restrições ao uso da terra na faixa de $150 \mathrm{~km}$ de largura a partir do limite internacional terrestre do Brasil. Além das normas mencionadas, a faixa de fronteira brasileira é regionalizada pelo Ministério da Integração Nacional em programas

5 A PNDR "tem o duplo propósito de reduzir as desigualdades regionais e de ativar os potenciais de desenvolvimento das regiões brasileiras, explorando a imensa e fantástica diversidade que se observa nesse país de dimensões continentais", visando potencializar a dinâmica e a distribuição da produção regional (MIN, 2011).

$6 \mathrm{CF} / 88$, Artigo $20, \S 2^{\circ}$ : A faixa de até cento e cinquenta quilômetros de largura, ao longo das fronteiras terrestres, designada como faixa de fronteira, é considerada fundamental para defesa do território nacional, e sua ocupação e utilização serão reguladas em lei. 


\section{2}

como o PDFF - Programa de Desenvolvimento da Faixa de Fronteira.

Cabe lembrar que a extensão da faixa de fronteira estabelecida nos territórios paraguaio e boliviano difere da brasileira. As legislações internas dos respectivos países determinam a área de $50 \mathrm{~km}$ de faixa de fronteira a partir do limite internacional (Artigo $1^{\circ}$ da Lei paraguaia n. 2.532/2005 e Artigo $4^{\circ}$ da Lei boliviana n. 100/2011). Apesar disso, cabe destacar que a legislação paraguaia para a faixa de fronteira até hoje não foi aplicada de fato.

Dentre os três arcos existentes na fronteira brasileira, o presente trabalho trará um enfoque sobre o Arco Central (mapa 1), abordando os impactos decorrentes dos projetos da IIRSA-COSIPLAN na área em questão. O Arco Central é composto pelas faixas de fronteira dos estados de Rondônia, Mato Grosso e Mato Grosso do Sul, sendo marcado pelo caráter de transição entre a Amazônia e o Centro-Sul do país e sua posição central no subcontinente. Este arco abrange áreas de duas grandes bacias hidrográficas sul-americanas, a Bacia Amazônica e a Bacia do Paraná-Paraguai.

Historicamente, segurança e desenvolvimento foram as lentes utilizadas para conceber a ótica do pensamento estratégico brasileiro na faixa de fronteira. A lente do desenvolvimento é materializada nos programas de desenvolvimento e na concessão de incentivos especiais. Nesse sentido, a CDIF - Comissão de Desenvolvimento da Faixa de Fronteira - e o Programa de Desenvolvimento da Faixa de Fronteira, ligados ao Ministério da Integração Nacional (MIN), são ferramentas utilizadas a fim de articular as dimensões (social, econômica e cultural) da questão da soberania nacional com o desenvolvimento regional.

Mapa 1: Arcos de fronteira do Brasil

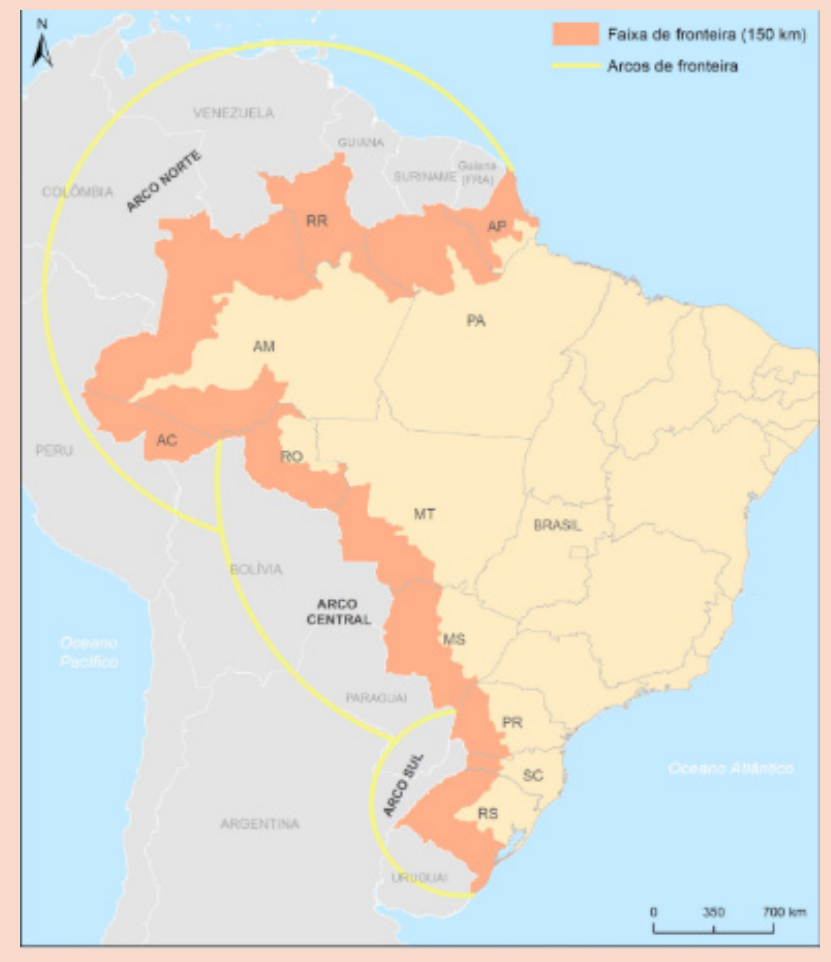




\section{3}

Autor: Camilo Pereira Carneiro, 2018.

De acordo com Cervo (2008), no decorrer do governo Lula da Silva ${ }^{7}$ (20032010), a questão fronteiriça passou a integrar a agenda do desenvolvimento regional por meio do processo de integração, sendo definido como tema prioritário, caracterizando uma das estratégias para viabilizar e fortalecer o desenvolvimento econômico das populações em situação de vulnerabilidade. Ademais, a zona de fronteira passou a receber um novo olhar por parte do governo brasileiro, sendo esta reconhecida por suas carências, mas, por outro lado, sendo considerada preponderante para o processo de integração sul-americano. O governo Lula aprofundou os elementos do chamado Estado logístico iniciado no período Cardoso, dando continuidade e ampliando várias estratégias de inserção internacional iniciadas pela administração anterior (CERVO, 2008).

É importante destacar que a integração regional sul-americana foi incorporada à agenda de política externa brasileira devido aos reflexos dos processos de redemocratização dos países da região, bem como à ascensão de políticas neoliberais nesses países, além da reaproximação com a Argentina.

\subsection{Os Reflexos dos Projetos da IIRSA-COSIPLAN no Arco Central}

De acordo com Senhoras (2008), a IIRSA-COSIPLAN é baseada no conceito de sustentabilidade econômica, social e ambiental em escala continental, além de seguir um modelo de desenvolvimento para fora, pautado na concepção espacial de eixos de integração e desenvolvimento ${ }^{8}$. No Arco Central, particularmente, merecem destaque os eixos: Capricórnio, Hidrovia Paraguai-Paraná e Interoceânico Central.

Considerando os eixos em questão, torna-se pertinente identificar seus objetivos e ameaças:

a) Eixo Capricórnio (figura 1): é voltado para melhoria da malha ferroviária e rodoviária, além de projetar o estabelecimento de interconexão com a hidrovia Paraná-Paraguai. Por sua vez, representa ameaça de cunho ambiental para o Cerrado, a Mata Atlântica e o Pantanal.

7 De acordo com Cervo (2008), o Governo Lula aprofundou os elementos do chamado Estado logístico, de modo a ampliar as estratégias de inserção internacional advindas do governo anterior.

8 A referida ideia dos eixos de integração foi defendida pelo ex-presidente da Cia. Vale do Rio Doce, Eliezer Batista da Silva, em um trabalho, de 1995, intitulado Infraestrutura para o Desenvolvimento Sustentado e Integração da América do Sul. 
Figura 1: Eixo Capricórnio

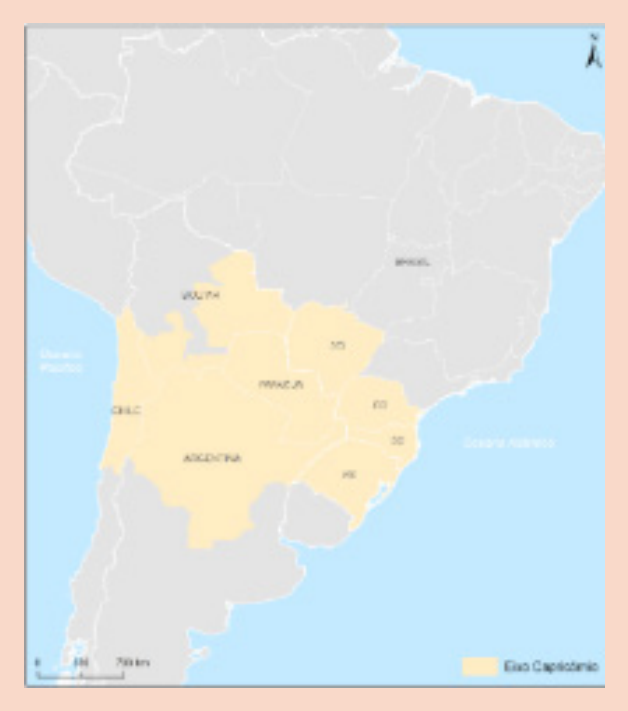

b) Hidrovia Paraná-Paraguai (figura 2): possibilita a navegação de barcaças durante $o$ ano inteiro, visando minimizar os custos de transporte para exportação de minérios e grãos, representando ameaça ambiental ao Pantanal e ao Cerrado.

Figura 2: Eixo Hidrovia Paraná-Paraguai

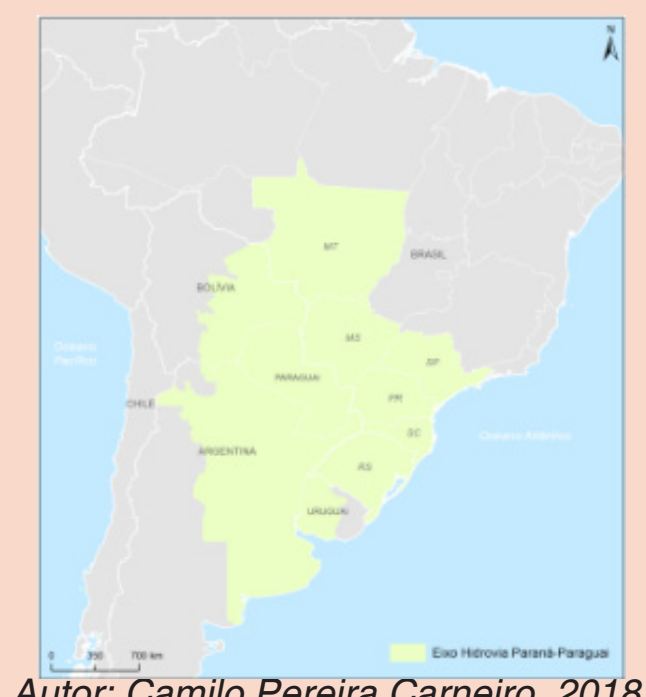

c) Interoceânico Central (figura 3): visa o desenvolvimento e articulação dos polos industriais de Belo Horizonte, Rio de janeiro e São Paulo com Mato Grosso, Mato Grosso do Sul, a região petroleira e de sojicultura da Bolívia e o 


\section{5}

Oceano Atlântico, sendo uma ameaça ambiental ao Cerrado, à Mata Atlântica e ao Pantanal.

Figura 3: Eixo Interoceânico Central

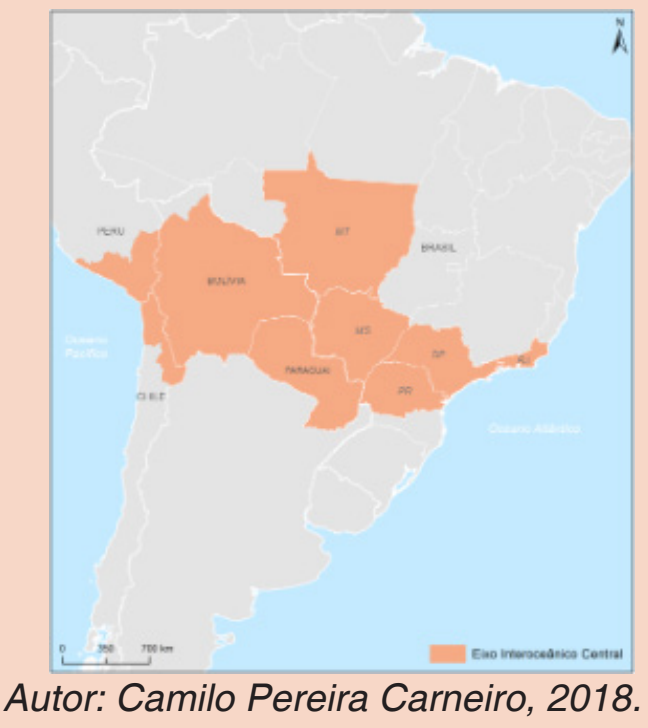

A necessidade de escoamento de grãos, sobretudo a soja, no estado de Mato Grosso é utilizada para justificar cinco hidrovias, duas ferrovias e pelo menos uma rodovia, a BR-163. Atrelada aos interesses da indústria da soja, a IIRSA-COSIPLAN, através de projetos de infraestrutura multimodal, torna possível o escoamento eficiente da produção de soja do estado, sobremaneira porque os custos de transporte representam mecanismo importante da competitividade internacional.

No âmbito do transporte rodoviário, a BR-163 (trecho entre a divisa MT/ PA e Santarém) se apresenta como projeto de grande relevância econômica e ambiental. A obra teve seu início em 1991 e sua conclusão estava originalmente prevista para o ano de 2015 - sendo sua conclusão prorrogada para 2018 -, entretanto, até a presente data a obra não foi concluída. O projeto é o principal promotor da agroindustrialização no estado do Mato Grosso, perpassando por 71 municípios (6 no Amazonas, 37 no Mato Grosso e 28 no Pará), somando 1.232 mil quilômetros.

No tocante à questão do desenvolvimento das cidades atrelado à sustentabilidade ambiental, o projeto se mostra inviável, pois, caso realmente fosse implementado conforme o planejado, estima-se que de 120 a 270 mil quilômetros quadrados de selva seriam desmatados, refletindo na emissão de bilhões de toneladas de gás carbônico na atmosfera (BRASIL, 2006). A magnitude desses impactos atinge de modo agressivo o bioma Cerrado, que concentra as nascentes que alimentam e formam grandes rios das bacias do Amazonas, do São Francisco e do Prata. Além do mais, grande parcela da agricultura brasileira depende da manutenção da floresta Amazônica9 ${ }^{9}$ (CEBRAC, 2002).

9 Reguladora das chuvas do Centro-Oeste e do Sudeste, sem a quais as principais regiões agrícolas do 
Por sua vez, os eixos Interoceânico Central ${ }^{10}$ e Hidrovia Paraná-Paraguai estão intimamente ligados, de modo a caracterizar as rotas bioceânicas do Mato Grosso do Sul. O eixo Interoceânico Central é voltado tanto para a exploração agropecuária quanto industrial ${ }^{11}$, além de ser constituído por intensa atividade mineral extrativista (estanho, zinco, ferro e cobre). Juntos, os projetos mencionados consolidam a eficácia e a multimodalidade dos transportes, buscando a integração regional via rotas bioceânicas, sendo estas ferramentas de estratégia na busca da competitividade econômica global. Na concepção da IIRSA-COSIPLAN:

A provisão destes serviços de infraestrutura busca promover o desenvolvimento de negócios e correntes produtivas com grandes economias de escala ao longo destes Eixos, seja para o consumo interno da região ou para a exportação aos mercados globais. Da mesma forma, persegue-se o ordenamento e desenvolvimento harmônico do espaço sul-americano, facilitando o acesso a zonas de alto potencial produtivo que se encontram atualmente isoladas ou subutilizadas devido à deficiente provisão de serviços básicos (IIRSA, 2004, p.17).

Não obstante, os projetos justificados pelo governo como vetores do desenvolvimento causam grandes impactos ambientais, muitas vezes omitidos e ofuscados por uma narrativa imbuída do ideário da integração regional. As grandes monoculturas provocam impactos irreversíveis não só nos microclimas e no ciclo natural das águas, como também na qualidade e disponibilidade hídrica, afetando aquíferos e a recarga de lençóis freáticos (CEBRAC, 2002).

Cabe destacar que as áreas ocupadas pela monocultura de exportação refletem em perda de diversidade biológica e cultural, além de representar grandes prejuízos à flora e à fauna, causando migração e até mesmo extinção de espécies. As populações locais, por conseguinte, também são impactadas por este processo, de modo que, ao serem compulsoriamente submetidas a se deslocarem, deixam seus meios de subsistência, o que reflete em impactos econômicos, sociais e culturais (CEBRAC, 2002).

Por outro lado, o discurso dos representantes dos organismos envolvidos nos projetos é de que as comunidades locais serão consideradas na implementação dos empreendimentos e, ainda, que a tecnologia minimizaria os impactos socioambientais. Entretanto, tem sido observado que as obras são escolhidas

Brasil se tornarão secas demais para a produção de grãos.

10 Eixo transversal composto por cinco países: Brasil, Bolívia, Chile, Paraguai e Peru. E ainda "compreende oito dos nove departamentos da Bolívia (exceto Pando); cinco estados do Brasil (Mato Grosso, Mato Grosso do Sul, Paraná, Rio de Janeiro e São Paulo); a primeira região do Chile; todo o Paraguai, e as províncias peruanas de Arequipa, Moquegua e Tacna. Tem uma superfície de 3.3 milhões de $\mathrm{km}^{2}$, ou seja, um total de $19 \%$ da superfície da América do Sul” (OLIVEIRA, 2010, p. 78).

11 Importante área caracterizada pela "soja e oleaginosas, cana-de-açúcar, papaias e produtos forrageiros, além da produção de cítricos como laranjas em São Paulo e de produtos animais, com importante participação na produção de carne de frango, carne de vaca e baby beef” (OLIVEIRA, 2010, p. 80). 
de acordo com critérios geoeconômicos (interesse da iniciativa privada, fluxo de comércio, local estratégico para a instalação, etc.) e, apenas de forma tênue, em segundo plano aparece a preocupação com os impactos socioambientais (CARNEIRO, 2016).

\section{OS PROJETOS IIRSA-COSIPLAN E A AUSÊNCIA DE PARTICI- PAÇÃO DAS COMUNIDADES LOCAIS}

Com vistas a articular o diálogo político de alto nível entre os governos dos países sul-americanos, foi criada, em 2008, pelos presidentes dos 12 países do subcontinente, a União das Nações Sul-Americanas (UNASUL) ${ }^{12}$. A organização tem como objetivo geral, inserido no Artigo 2 de seu Tratado Constitutivo, a construção participativa e solidária de uma sistemática organizacional de integração regional dos países pautada nos valores culturais, políticos, sociais e econômicos, a fim de eliminar desigualdades socioeconômicas, alcançar a inclusão social e promover a participação cidadã ${ }^{13}$.

Nesta perspectiva, a hoje combalida UNASUL estruturou-se mediante a composição de oito conselhos setoriais de nível ministerial. Sob os fundamentos e princípios impulsionadores da Iniciativa para a Integração da Infraestrutura Regional Sul-Americana (IIRSA), a UNASUL criou o Conselho Sul-Americano de Infraestrutura e Planejamento (COSIPLAN), que tem como atribuição a articulação de planejamentos estratégicos para instalação e modernização de infraestruturas capazes de fortalecer o desenvolvimento e a integração dos países da UNASUL, sobretudo através de planos logísticos dos mercados de energia, transportes e comunicações.

Dessa forma, o COSIPLAN, em 2011, lançou dois grandes planos de ação frente ao desenvolvimento da integração física de construção e operacionalização de infraestruturas entre os países sul-americanos, a saber: o Plano de Ação Estratégico (PAE) - com vigência de 2012 a 2022 - e a Agenda de Projetos Prioritários de Integração (API), esta última estimada em U\$ 13,6527 bilhões em investimentos, contemplando 31 projetos de infraestrutura (COSIPLAN, 2018).

A operacionalização dos projetos de infraestrutura nos setores de comunicação, transporte e energia foi delineada a partir do desenvolvimento e aplicação da "Metodologia de Planejamento Territorial Indicativo", que se baseou na iden-

12 Integram a UNASUL: Argentina, Bolívia, Brasil, Chile, Colômbia, Equador, Guiana, Paraguai, Peru, Suriname, Uruguai e Venezuela.

13 Dentre os objetivos específicos da UNASUL, destacam-se o desenvolvimento de uma infraestrutura para conexão dos países da América do Sul e dos seus povos de acordo com critérios de desenvolvimento social e econômico sustentáveis, "a proteção da biodiversidade, dos recursos hídricos e dos ecossistemas (...)" e "a participação cidadã, por meio de mecanismos de interação e diálogo entre a UNASUL e os diversos atores sociais na formulação de políticas de integração sul-americana" (Artigo 3, "e", "g" e "p", Tratado Constitutivo da UNASUL, 2008). 


\section{8}

tificação dos Eixos de Integração e Desenvolvimento (EID) ${ }^{14}$, dividindo metodologicamente o subcontinente e ordenando o Portfólio de Projetos (COSIPLAN, 2018).

Os EID configuram áreas multinacionais de influência, com a proposta de delimitar e evidenciar especificidades regionais quanto aos recursos naturais, assentamentos humanos, áreas produtivas e serviços logísticos, com intuito de facilitar fluxos de bens, serviços, pessoas e informações, seja no âmbito interno do subcontinente ou para o resto do mundo (COSIPLAN, 2018).

Não obstante, o aspecto de desenvolvimento sustentável dos EID, sensível às características socioambientais específicas das localidades, esmorece diante de enredos de intencionalidades da UNASUL, dirigidas por blocos hegemônicos - de decisões neoclássicas autônomas - que renegam a diversidade de territorialidades, adotando estratégias intolerantes aos interesses não mercantis (HIRT, 2014).

Cabe destacar que a regionalização transnacional entre os países sul-americanos representa, por um lado, a implementação de estratégias geopolíticas de globalização por fluxos comerciais e por outro extremo reflete a composição de arenas de "aglomerações competitivas ou polos de desenvolvimento em simultâneo à produção de espaços de marginalização" (SENHORAS, 2008).

Os impactos regionais provenientes da execução dos projetos da IIRSA-COSIPLAN têm gerado críticas quanto ao cumprimento dos objetivos originais - gerais e específicos - da própria UNASUL, especialmente no tocante à participação das comunidades locais e a sustentabilidade ${ }^{15}$. As obras de infraestrutura da IIRSA-COSIPLAN têm impactado áreas protegidas e a falta de integração entre projeto econômico e projeto social tem repercutido negativamente, reposicionando o papel dos eixos infraestruturais na organização territorial da América do Sul (TAVARES, 2016).

Para Porto-Gonçalves e Araújo Quental (2012), a IIRSA-COSIPLAN dispõe de projetos de natureza controversa à sustentabilidade, haja vista as desconsiderações em torno da valoração da diversidade ecológica e cultural dos ambientes e das comunidades tradicionais, tratando áreas de fronteira como meros "vazios demográficos". A complexidade dos biomas, domínios morfoclimáticos e

14 Atualmente são dez os Eixos de Integração da IIRSA-COSIPLAN: Andino, Andino do Sul, Capricórnio, Hidrovia Paraguai-Paraná, Amazonas, Escudos das Guianas, Sul, Interoceânico Central, MERCOSUL-Chile e Peru-Brasil-Bolívia. Os EID foram criados para distribuir e reorganizar as potencialidades econômicas dos territórios sul-americanos, elevando o nível de competitividade regional na obtenção de benefícios resultantes da logística de escoamento dos diversos setores da economia, integrando as regiões isoladas com o viés de facilitar a transação de produtos, sobretudo no mercado externo aos demais continentes.

15 Tratado Constitutivo da UNASUL:

Artigo 3

Objetivos específicos:

A União de Nações Sul-americanas tem como objetivos específicos:

[...]

p) a participação cidadã, por meio de mecanismos de interação e diálogo entre a UNASUL e os diversos

atores sociais na formulação de políticas de integração sul-americana. 
a existência de específicas comunidades tradicionais são abordados de forma secundária nos documentos da IIRSA-COSIPLAN e pelos órgãos fomentadores, de maneira a representar desafios meramente da engenharia ${ }^{16}$ (PORTO-GONÇALVES; QUENTAL, 2012).

Paradoxalmente, o poder de decisão nos projetos de elaboração e execução da construção de infraestruturas da IIRSA-COSIPLAN restringiu-se às vontades executivas e de influência do setor privado ${ }^{17}$, sobretudo brasileiro, quando da ocorrência nas últimas décadas de transformações evolutivas das normas constitucionais dos países sul-americanos proclamadas sob preceitos democráticos e republicanos, exaltando a participação pública em matéria social e ambiental, como deferência ao Estado de Direito (FLÓREZ, 2007).

Atualmente, diversos projetos da IIRSA-COSIPLAN já vêm sendo executados sem prévia e ampla participação popular ${ }^{18}$, sendo responsáveis por perdas socioambientais e socioculturais, justificadas pela narrativa oficial que exalta as "vantagens mercantis". Como afirma Flórez (2007):

Las interrelaciones entre ambiente e infraestructura se posponen hasta cuando exista "concordancia con las posibilidades reales de financiamiento e inversión". Es decir, el aspecto ambiental, que debiera ser un objetivo prioritario en un plan de integración que consultara las aspiraciones de la población, se coloca en un segundo plano, por cuanto lo primero es la integración en inversión a cargo del BID, la CAF y el FONPLATA y aumentar el papel del sector privado en la financiación de los proyectos y en su operación (FLÓREZ, 2007, p. 1).

Por trás dos projetos da IIRSA-COSIPLAN, como sustenta Carneiro (2014), grandes empresas brasileiras de infraestrutura, com apoio do BNDES, passaram a operar de maneira a atender objetivos diversos daqueles da própria iniciativa. Objetivos muitas vezes contrários aos interesses das comunidades locais afetadas pelos projetos.

\footnotetext{
16 Analisando discurso realizado por Carlos Lessa em 2003, então presidente do BNDES, Porto-Gonçalves e Quintal criticam a indiferença com as populações minoritárias e vulneráveis quando justificam os conflitos socioambientais sob uma lógica territorial que considera a existência de "vazios demográficos" e de "hinterlândia ainda não ocupada".

17 Nas lições de Raúl Zibechi (2006), "Desde el punto de vista de superar las barreras normativas de los estados, la IIRSA profundiza la estrategia neoliberal de desregulación y debilitamiento de los estados nacionales. Adecuar las legislaciones nacionales a las necesidades del comercio mundial supone homogeneizar las normas. De esa manera cada región y cada país pierde sus rasgos diferenciadores y los estados pierden autonomia frente a las multinacionales y los estados del primer mundo".

18 De acordo com Margarita Flórez (2007): "La IIRSA ya es un hecho, sin que los habitantes de las regiones incluidas hayan tenido una participación proporcionada a su envergardura".

19 Em tradução livre: "As inter-relações entre meio ambiente e infraestrutura são adiadas até que haja "concordância com as possibilidades reais de financiamento e investimento". Ou seja, o aspecto ambiental, que deve ser um objetivo prioritário em um plano de integração que consulte as aspirações da população, é colocado em segundo plano, já que o primeiro é a integração do investimento pelo BID, CAF e o FONPLATA e aumentar o papel do setor privado no financiamento de projetos e em sua operação".
} 


\section{0}

Empresas privadas brasileiras responsáveis por obras de engenharia da IIRSA-COSIPLAN, como Andrade Gutierrez, Odebrecht e Camargo Corrêa, juntamente com o BNDES, foram as principais protagonistas da IIRSA-COSIPLAN até 2014 , chegando a deter o controle de diversos setores econômicos ${ }^{20}$ sul-americanos que, interligados entre si comungam de interesses logísticos e comerciais - principalmente no tocante ao escoamento da produção -, influenciando a governabilidade institucional de políticas públicas.

Assim, as obras da IIRSA-COSIPLAN acabam por representar o domínio do setor privado sobre o interesse público, resultando em expropriações de diversas comunidades - geralmente pobres - e sendo defendidas pela narrativa oficial da integração regional e do desenvolvimento para as localidades como se os projetos da iniciativa fossem trazer vantagens comerciais e, consequentemente, melhorias na vida das comunidades locais. Na definição de Braga (2013), o papel logístico do Estado brasileiro, então, representado pela expansão da IIRSA-COSIPLAN, serviu para respaldar a imposição das territorializações dos grandes negócios sobre os interesses das sociedades locais.

O que se observa nos megaprojetos de infraestrutura é que os mecanismos de participação popular são fictos, cumprindo mero procedimento formal, desprovido de poder deliberativo ou consultivo. Por vezes, a participação ocorre em avançada fase de procedimento decisório ou com decisões já tomadas, exprimindo uma fragilidade institucional no atendimento de preceitos republicanos.

Nesse sentido, no tocante à construção do complexo Hidrelétrico Rio Madeira, de responsabilidade das empresas Odebrecht e Eletrobrás Furnas, Ribeiro e Moret (2014) denunciam a realização de poucas audiências públicas e ainda a elaboração incompleta e às pressas do estudo de impacto ambiental para instalação da UHE de Santo Antônio na região de Porto Velho-RO. A participação popular com poder decisivo nas matérias ambientais e urbanísticas, prevista não só nos objetivos traçados pela UNASUL, mas também como direito fundamental nos ordenamentos jurídicos sul-americanos - adoção do modelo de Estado Democrático de Direito - é mecanismo que fortalece o direito à igualdade, a defesa dos ecossistemas e a preservação do patrimônio cultural, devendo ser garantido pelo Estado, principalmente nos projetos de sua responsabilidade.

\section{IMPACTOS AMBIENTAIS E SOCIOECONÔMICOS DA IIRSA- -COSIPLAN}

Políticas de integração regional implementadas por meio de novas rotas de distribuição e expansão de mercados - como é o caso da IIRSA-COSIPLAN - que deem ênfase ao desenvolvimento humano, principalmente nos setores desfavorecidos do interior dos países integrantes pressupõem obediência às di20 Alessandro Biazzi Couto dimensiona a potencialidade destas empresas privadas responsáveis pelos serviços de engenharia da IIRSA-COSIPLAN (COUTO, 2008, pp. 82-83). 


\section{1}

versidades locais e à proteção das comunidades. A inobservância de aspectos sociais, políticos e econômicos, reflete diretamente as deficiências do processo de planejamento regional, especialmente no que diz respeito à perspectiva de sustentabilidade e à insuficiência da participação da sociedade civil, sob pena de violação aos direitos humanos pelo domínio do capital.

O Arco Central ostenta uma riqueza biológica ímpar presente no Pantanal e no bioma Amazônico, bem como abarca a multiculturalidade de específicas comunidades tradicionais: ribeirinhas, pantaneiras, indígenas, quilombolas e pequenos criadores de gado. Considerando a biodiversidade e a sociodiversidade do Arco Central, os projetos da IIRSA-COSIPLAN para esta parte da fronteira brasileira deveriam levar em conta os anseios locais, os impactos primários e secundários aos povos e aos ecossistemas desta parte da fronteira por meio de estudos técnicos (UNASUL, 2008). Não obstante, isto não vem ocorrendo, como pode ser evidenciado no caso da construção de hidrelétricas na Amazônia.

O projeto do complexo Rio Madeira, por exemplo, consiste na construção de duas grandes hidrelétricas, Jirau e Santo Antônio, entre as cidades de Porto Velho e Abunã no estado da Rondônia, extremo norte do Arco Central da faixa de fronteira do Brasil, além da implantação de sistemas de hidrovias nas bacias dos rios Madeira, Beni, Guaporé, Mamoré, Orthon e Madre de Dios, percorrendo $4.225 \mathrm{~km}$ pelo Brasil, Bolívia e Peru.

As duas usinas hidrelétricas provocaram inundações históricas e o aumento de erosões - inicialmente foi prevista a inundação de $529 \mathrm{~km}^{2}$-, em contrapartida haveria uma produção de 6.450 megawatts, e um investimento de cerca de $\mathrm{R} \$ 20$ bilhões. Não obstante, os custos com a degradação dos ecossistemas e a injustiça ambiental impostos às comunidades ribeirinhas são incalculáveis. A apropriação dos recursos naturais e a degradação do bioma são diretamente absorvidas pelos atores locais nas cercanias de Porto Velho - ribeirinhos, pescadores artesanais - e têm causado grande prejuízo à agricultura familiar (CAVALCANTE; SANTOS, 2012).

A alteração biológica do Rio Madeira impôs o deslocamento forçado de diversas famílias e colônias de pescadores aos centros urbanos, fato ocorrido em comunidades como Teotônio e Amazonas. Tradicionalmente, o manejo dos recursos naturais simboliza, para estes grupos, seu modo de subsistência e reprodução de sua cultura. Migrando à urbe, são submetidos à dependência de empregos e salários, bem como à rotina citadina ${ }^{21}$.

O aproveitamento dos rios também diverge dos interesses socioambientais e do interesse coletivo ao desenvolvimento. A intervenção no curso dos rios por métodos de dragagem, obras nas margens, uso de explosivos, entre outros, repercute no ecossistema hídrico e florestal, tal como transparecem interesses alheios à sustentabilidade. A hidrovia estimula a expansão do agronegócio que

21 Glass (2006) cita a construção da UHE de Samuel, no rio Jamari, nos anos de 1980, como exemplo de catástrofe socioambiental, que repercutiu no aprofundamento e aumento da miséria na periferia de Porto 


\section{2}

exaustivamente, ano a ano, incide no desmatamento e destruição de ecossistemas.

O complexo Rio Madeira, como sustentado por Paim (2003), além de favorecer um seleto grupo de produtores rurais com a redução dos custos no transporte de commodities por rotas hidroviárias, beneficia também indústrias estrangerias de fabricação de máquinas e equipamentos, como a alemã Voith Siemens e a suíça Asea Brown Boveri, além da construtora Odebrecht e a estatal Furnas Centrais Elétricas com a implantação das UHEs.

A interferência do interesse privado capitalista nas políticas públicas de integração, como acontece na IIRSA-COSIPLAN, aflige também ambientalistas na região do Pantanal. A construção da Hidrovia Paraguai-Paraná suscita incertezas quanto à dimensão total dos impactos primários e secundários.

O projeto da Hidrovia Paraguai-Paraná prevê a navegabilidade nos rios Paraguai e Paraná em um percurso de 3.400 km que liga a cidade de Cáceres-MT até Nueva Palmira, no Uruguai, desaguando no Oceano Atlântico. As intervenções hídricas necessárias a este projeto compreendem a ampliação, aprofundamento e retificação de curvas do Rio Paraguai - em 114 áreas do Pantanal - executadas por meio de dragagens, construções às margens do rio e implantação de portos (BORGES, 2002), provocando violenta alteração no regime hídrico e no bioma Pantanal. Nesse sentido, Budasoff (2005) acusa o interesse de grandes investidores do agronegócio no barateamento dos custos no transporte de grãos.

Segundo o referido autor, empresas como Cargill, Bunge, Archer Daniels Midland (ADM) e Louis Dreyfus, dominantes no agronegócio mundial, detêm grande interesse - junto aos produtores rurais - na operacionalização desta hidrovia. Além dos impactos diretos sobre os rios, notam-se conflitos como a expansão do agronegócio sobre os biomas Pantanal e Cerrado, assim como sobre os Chacos boliviano e paraguaio, além do aumento na extração de madeira e o agravamento dos impactos irreversíveis às comunidades ribeirinhas e indígenas da região (PAIM, 2003).

A atuação de ONGs ambientais contra a execução da Hidrovia Paraguai-Paraná obteve forte repercussão política internacional, provocando várias interrupções na execução do projeto. Inobstante, a força do lobby rodoviarista também comunga do mesmo interesse. Indústrias dos setores automobilístico, de engenharia rodoviária e petroquímico (entre elas a Petrobras) partilham do mesmo interesse em inviabilizar o avanço da hidrovia, tendo em vista os impactos econômicos que incidem sobre grupos empresariais com a adoção de alternativas no transporte de cargas. A dificuldade da implementação de um sistema multimodal de transportes recebe forte influência política do setor rodoviarista, repercutindo em esquemas de corrupção envolvendo financiamentos de

Velho, fruto da negligência de direitos e assistência a cerca de 650 famílias. 


\section{3}

campanhas políticas com o lobby deste setor, cujos integrantes vêm sendo alvo de diversas investigações por parte da Polícia Federal e do Ministério Público (AGÊNCIA SENADO, 2018).

A realidade da integração regional promovida pela IIRSA-COSIPLAN revela graves problemas e situações de injustiça social, ambiental e econômica, assimétricas aos objetivos construídos no Tratado Constitutivo da UNASUL, além de uma série de violações de direitos humanos relativos às liberdades individuais, à dignidade da pessoa humana, à preservação da cultura, ao meio ambiente equilibrado, à moradia, dentre outros.

\subsection{As críticas aos projetos da IIRSA-COSIPLAN}

Em 2003, o projeto de fortalecimento da integração da América do Sul passou a ter como protagonista o BNDES. O referido projeto teve como objetivos principais a capacitação tecnológica e humana mediante cooperação e o fortalecimento do poder de negociação dos países; o ganho na escala de produção; a atração de investimentos, sobretudo em infraestrutura e expansão do comércio entre os países (BNDES, 2004). Considerando os pressupostos da IIRSA-COSIPLAN, têm-se notado um avanço apenas nas questões econômicas - dada a lógica capitalista -, de modo que apenas um limitado grupo de pessoas e empresas tem sido beneficiado de forma significativa com os projetos propostos.

Não há um consenso na literatura especializada sobre o impacto dos financiamentos do BNDES para o aprofundamento da integração regional. Ao considerar as inúmeras divergências sobre a validade da IIRSA-COSIPLAN como fomento efetivo do processo integracionista, é possível verificar a ausência de uma base de dados pública em que se possa ter acesso às obras financiadas pelo BNDES na América do Sul, devido à necessidade de resguardar o sigilo bancário das empresas.

Ademais, à IIRSA-COSIPLAN é atribuída grande responsabilidade por danos socioambientais, decorrentes de projetos de geração de energia e da criação de corredores de exportação dos recursos naturais do continente que favorecem sobremaneira as grandes empresas multinacionais (CARVALHO, 2012). Além do BNDES e dos governos dos 12 países sul-americanos, muitos são os atores envolvidos na implementação e formulação da IIRSA-COSIPLAN, advindo dos setores empresarial e financeiro. Dentre os protagonistas na iniciativa, destacam-se: Banco Interamericano de Desenvolvimento (BID); Corporação Andina de Fomento (CAF); Fundo Financeiro para o Desenvolvimento da Bacia do Rio da Prata (FONPLATA), e empresas como Odebrecht; Petrobras; Andrade Gutierrez; Queiroz Galvão; Camargo Corrêa, OAS, Vale; General Eletric (GE) e ALL (SILVA, 2013).

Cabe destacar que a partir de 2014, com o advento da Operação Lava-Jato e a crise política que culminou no golpe branco de 2016, no Brasil, o BNDES 
deixou de ser um ator protagonista no processo de integração sul-americano e na IIRSA-COSIPLAN. A partir de 2016, os novos protagonistas da IIRSA-COSIPLAN, no lugar do banco público brasileiro, passaram a ser o BID, a CAF e o FONPLATA.

No âmbito do processo de integração da infraestrutura regional, muitas são as críticas concernentes à presença de parte das obras da IIRSA-COSIPLAN no Programa de Aceleração do Crescimento (PAC) ${ }^{22}$. Autores como Hirt (2013) e Novoa (2009) caracterizam a postura brasileira como subimperialista. Por sua vez, Braga (2013) e Luce (2007) definem a atuação brasileira na região como um projeto de potência regional pautado em interesses nacionais que acentua as assimetrias socioeconômicas na América do Sul. Para os autores em questão, a postura brasileira é interpretada de maneira negativa no que tange aos impactos da aspiração brasileira de liderança à frente do processo de integração, de modo a beneficiar os interesses econômicos brasileiros sob o discurso do desenvolvimento regional pregado pelo Brasil (PAZ, 2015).

Por sua vez, a Ease-IIRSA ${ }^{23}$, como ferramenta metodológica de avaliação ambiental, ressalta a necessidade de incorporação de uma agenda ambiental e social "que promova o desenvolvimento sustentável através da identificação de tendências, riscos e oportunidades que poderiam ser geradas nos territórios afetados" (DIZ; SOUZA, 2015).

De acordo com Diz e Souza (2015),

[...] a Ease também dita que devem ser feitas recomendações estabelecendo estratégias de mitigação de impactos e linhas de investimento que gerem opções de desenvolvimento sustentável e que facilitem a abertura de um espaço para o diálogo entre os governos e os atores-chave das áreas afetadas. No entanto, o que ocorre é que esta metodologia não está sendo devidamente aplicada e não há a inclusão dos atores-chave. Esta avaliação ambiental estratégica tem sido utilizada como uma forma de suprir lacunas nos processos de licenciamento ambiental quando na realidade deveriam ser ferramentas que definissem previamente a necessidade ou não destes projetos (DIZ; SOUZA, 2015, p. 16).

De acordo com Senhoras, Moreira e Vitte (2008), esse reflexo negativo gera um déficit democrático que tem impacto, sobretudo, no processo de formulação do planejamento da iniciativa, bem como em sua implementação. Corrobo-

22 "A ligação entre o PAC e a IIRSA seria possível devido ao fato de que $60 \%$ dos projetos da IIRSA seriam obras nacionais com algum impacto em países vizinhos e os demais empreendimentos binacionais seriam ferrovias, hidrovias, túneis, passagens de fronteira, transmissão de energia e pontes" (CARVALHO, 2012, p.7).

23 A Ease (Evaluación Ambiental y Social con Enfoque Estratégico) tem por objetivo "identificar com um enfoque preventivo baseado em ações complementares para potencializar, desde o ponto de vista socioambiental e cultural, os efeitos positivos dos projetos e minimizar seus impactos negativos" (DIZ; SOUZA, 2015). 


\section{5}

rando com este entendimento, Diz e Souza (2015) afirmam que quando projetos de grande impacto são elaborados sem consulta ou participação da população local a identificação das prioridades sociais torna-se insustentável, assim como a governabilidade.

\section{CONSIDERAÇÕES FINAIS}

Embasadas na narrativa oficial da integração regional e do desenvolvimento da zona de fronteira, grandes instituições de financiamento e fomento estão a atuar em favor de seus interesses, de modo que o discurso da integração e do desenvolvimento perde sentido quando se verifica a execução de obras que desconsideram os aspectos socioambientais, em especial em zonas fronteiriças.

Ademais, autoridades governamentais se valeram, durante os anos em que o Partido dos Trabalhadores esteve no poder, do discurso de integração regional e da expansão da projeção do país no cenário internacional, como líder do subcontinente, estabelecendo relações de interesse com os países sul-americanos através dos projetos da IIRSA-COSIPLAN. Naquele momento, o investimento em países vizinhos era parte da política externa do Brasil no intuito consolidar sua liderança regional. Estratégia que foi interrompida com a crise político-econômica iniciada em 2014, que fez com que o BNDES deixasse de ser o principal financiador da IIRSA-COSIPLA, abrindo espaço para outros atores como o CAF, o FONPLATA e o BID. Com a mudança de governo, o Brasil passou a ter uma nova política externa, voltada à subordinação aos tradicionais países centrais - EUA, UE e Japão. No entanto, o que se percebe é que independente do viés da política externa (progressista ou conservadora), grande parte dos projetos da IIRSA-COSIPLAN segue sendo executada sem as devidas consultas às populações locais, deixando de considerar os estudos de viabilidade e impacto ambiental, o que reflete frequentemente em degradação de biomas, migração de populações, extinção de espécies dentre outros reflexos negativos.

Esses reflexos têm incidência direta no andamento de algumas obras, que acabam por permanecerem inacabadas sob o pretexto de inviabilidade ambiental ou pressão popular, quando o real motivo inviabilizador seria a falta de interesse ou de investimento das instituições de financiamento, aliado à discordância ou transição de governos, que resultam na descontinuidade de projetos. Dessa forma, ainda que os projetos da IIRSA-COSIPLAN sejam dotados de relevância econômica e estratégica, sobretudo no que diz respeito à integração regional por meio de infraestrutura, as preocupações ambientais têm ficado em segundo plano. 


\section{6}

\section{REFERÊNCIAS}

AGÊNCIA SENADO. País precisa romper com lobby rodoviário para ter um modelo racional de transporte, conclui debate. Senado Federal. Disponível em: $<$ https://www12.senado.leg.br/noticias/materias/2018/06/27/pais-precisa-romper-com-lobby-rodoviario-para-ter-um-modelo-racional-detransporteconclui-debate>. Acesso em: 09 ago. 2018.

BNDES. Integração da América do Sul: o BNDES como agente de política externa. Informe BNDES, Rio de Janeiro, n. 187, nov. 2004. Disponível em: <http:// www.bndes.gov.br/SiteBNDES/bndes/bndes_pt/Institucional/Publicacoes/Consulta_Expressa/Tipo/Informe_BNDES/>. Acesso em: 18 jul. 2018.

BOLIVIA. Ley no 100. Ley de Desarrollo y Seguridad Fronteriza. La Paz. 4 abr. 2011. Disponível em: <http://www2.congreso.gob.pe/sicr/cendocbib/con4_uibd. nsf/544EDED0F35DC91D05257C04006EFFD4/\$FILE/guadar.htm>. Acesso em: 09 ago. 2018.

BORGES, Janice Rodrigues Placeres. Um estudo de percepção de justiça e equidade, em aproveitamentos hídricos, de grupos sociais do Pantanal Mato-grossense - o caso da hidrovia Paraguai-Paraná. Tese de Doutorado. Escola de Engenharia de São Carlos-Universidade de São Paulo. São Carlos: EESC/ USP, 2002.

BRAGA, Jorge Luiz Raposo. O BNDES e o projeto de integração regional: internacionalização de empresas brasileiras no jogo político da América do Sul. In: EGAL, 14, 2013. Disponível em: <http://observatoriogeograficoamericalatina. org.mx/egal14/Geografiasocioeconomica/Geografiaeconomica/15.pdf>. Acesso em: 15 jul. 2018.

BRASIL. Constituição (1988). Constituição da República Federativa do Brasil. Brasília, 5 out. 1988. Disponível em: <http://www.planalto.gov.br/ccivil_03/constituicao/constituicaocompilado.htm>. Acesso em: 09 ago. 2018.

. Decreto Federal n. 85.064, de 26 de agosto de 1980. Regulamenta a Lei oㅡ 6.634, de 2 de maio de 1979, que dispõe sobre a Faixa de Fronteira. Brasília, 26 ago. 1980. Disponível em: <http://www.planalto.gov.br/ccivil_03/decreto/Antigos/ D85064.htm>. Acesso em: 09 ago. 2018. 


\section{7}

Lei Federal n. 6.634, de 02 de maio de 1979. Dispõe sobre a Faixa de Fronteira, altera o Decreto-Lei n. 1135, de 3 de dezembro de 1970, e dá outras providências. Brasília, 02 mai. 1979. Disponível em: <http://www.planalto.gov.br/ ccivil_03/leis/L6634.htm>. Acesso em: 09 ago. 2018.

Plano de Desenvolvimento Regional Sustentável para a Área de Influência da BR-163 (Cuiabá-Santarém). Brasília: Pres. da República, 2006.

BUDASOFF, Eliezer. Los dueños del rio - La hidrovía Paraguay-Paraná: el negocio de los recursos en América Latina. Buenos Aires: Taller Ecologista, abr. 2005.

CARNEIRO, Camilo P.; CRUZ, Milton. As potencialidades e os problemas das cidades dos Arcos Sul e Central da fronteira do Brasil. Anais do IV Seminário Internacional do Programa de Pós-Graduação em Sociologia. São Carlos: UFSCar, 2013.

CARNEIRO, Camilo P. Radiografia contemporânea dos arcos norte e sul da fronteira do Brasil. Fronteiras e relações Brasil-Uruguai. Porto Alegre: EdiPUCRS, 2015, pp. 129-146.

. Tríplice fronteira Brasil-Argentina-Paraguai: iniciativas de integração e cooperação por meio de infraestrutura, educação e saúde. II Seminário Internacional de Los Espacios de Frontera (II Geofrontera). Diferenciais e interconexiones. Posadas: Universidad Nacional de Missiones, 2014.

CARVALHO, Clarissa Barbosa Ramos Prudêncio de. O protagonismo do BNDES no financiamento da infraestrutura Sul-Americana durante o governo Lula: interface entre interesses domésticos e a política externa. In: I Seminário Nacional de Pós-Graduação de Relações Internacionais, Brasília-DF, p. 1-20, 2012.

CAVALCANTE, M. M. A.; SANTOS, L. C. Hidrelétricas no Rio Madeira-RO: tensões sobre o uso do território e dos recursos naturais na Amazônia. Confins, n. 15, 2012. Disponível em: <http://confins.revues.org/7758>. Acesso em: 16 out. 2018.

CEBRAC. Diretrizes para articulações e desenho de políticas públicas com o 


\section{8}

objetivo da defesa e uso sustentável da biodiversidade. Goiânia: Multigr, 2002.

COSIPLAN. Agenda de Projetos Prioritários de Integração - API 2011. Disponível em: <http://www.planejamento.gov.br/secretarias/upload/Arquivos/noticias/ spi/111130_Cosiplan_API_Agenda_de_projetos_prioritarios_de_integracao. pdf>. Acesso em: 13 jun. 2018.

Plano de Ação Estratégico 2012-2022 ajustado a 2017. Disponível em: <http://www.iirsa.org/admin_iirsa_web/Uploads/Documents/PAE_digital.pdf>. Acesso em: 10 ago. 2018.

. Ejes de Integración y Desarrollo. Disponível em: <http://www.iirsa.org/Page/ Detail?menultemld=68 >. Acesso em: 10 ago. 2018.

. Planificación Territorial. Disponível em: <http://www.iirsa.org/Page/Detail?menultemld=60>. Acesso em: 10 ago. 2018.

COUTO, Alessandro Biazzi. A atuação das grandes empreiteiras brasileiras na integraçãode infra-estrutura na América do Sul. In: VERDUN, Ricardo et alii (orgs.). Financiamento e magaprojetos: Uma interpretação da dinâmica regional sul-americana. Brasília: Inesc, 2008.

DIZ, Jamile B. M.; SOUZA, Laura Felipe de. O desenvolvimento regional e a proteção ambiental: uma análise da iniciativa para a integração da infraestrutura regional Sul-Americana. Revista de Direito Ambiental, São Paulo, v. 20, n. 77, 2015.

FLÓREZ, Margarita. La IIRSA: ¿Un lenguaje común? Ecoportal. 2007. Disponível em: <https://www.ecoportal.net/temasespeciales/globalizacion/la_iirsa_un_ lenguaje_comun/>. Acesso em: 09 ago. 2018.

GLASS, Verena. Complexo do Rio Madeira seria embrião de megaprojeto de infra para exportação. Repórter Brasil. 2006. Disponível em: <http://reporterbrasil. org.br/2006/09/complexo-do-rio-madeira-seria-embriao-de-megaprojeto-de-infra-para-exportacao/>. Acesso em: 09 ago. 2018. 


\section{9}

HIRT, Carla. O Papel do BNDES nas Políticas de Desenvolvimento e Integração Regional. Espaço 20 e Economia, n.3, p. 1-11. 2013. Disponível em: < http:// espacoeconomia.revues.org/423>. Acesso em: 15 jul. 2018.

O BNDES, o Desenvolvimento e o Grande Capital Nacional: uma análise escalar e territorial. Revista de Geografia (UFPE), v. 31, n. 2, 2014.

IIRSA. Planificación Territorial Indicativa. Cartera de Proyectos IIRSA, 2004.

LUCE, Mathias Seibel. O subimperialismo revisitado: a expansão do capitalismo brasileiro e a política de integração do governo Lula da Silva na América Latina. Dissertação de Mestrado. Programa de Pós-Graduação em Relações Internacionais da Universidade Federal do Rio Grande do Sul. Porto Alegre: UFRGS, 2007.

MIN. Ministério da Integração Nacional - Secretaria de Programas Regionais Proposta de Reestruturação do Programa de Promoção do Desenvolvimento da Faixa de fronteira (PDFF). <http://www.integracao.gov.br/c/document_library/get_file?uuid=e5ba704f-5000-43df-bc8e-01df0055e632\&groupld=10157>. Acesso em: 01 jun. 2018.

PNDR I - Política Nacional de Desenvolvimento Regional. Disponível em: $<$ http://www.mi.gov.br/politica-nacional-de-desenvolvimento-regional-pndr>. Acesso em: 01 jun. 2018

MORET, Artur de Souza, RIBEIRO, Aureni Moraes. A Construção da hidrelétrica de Santo Antônio e os impactos na sociedade e no ambiente. Revista Interfaces Científicas Humanas e Sociais, v. 2, p. 81-92, 2014.

NOVOA, Luis Fernando. O Brasil e seu 'desbordamento': o papel central do BNDES na expansão das empresas transnacionais brasileiras na América do Sul. In: Rosa Luxemburg Stiftunget et al. Empresas transnacionais brasileiras na América Latina: um debate necessário. p. 187-204, São Paulo: Ed. Expressão Popular, 2009.

OLIVEIRA, Valquiria de Araújo. A infraestrutura de transportes como política governamental para o desenvolvimento regional e a integração sul-americana: uma 
análise sobre as Rotas Bioceânicas em Mato Grosso do Sul. Dissertação de Mestrado. Programa de Pós-Graduação em Geografia da Universidade Federal da Grande Dourados. Dourados: UFGD, 2010.

PAIM, Elisangela Soldatelli. IIRSA: É esta a integração que nós queremos? Porto Alegre: Amigos da Terra, dez. 2003.

PARAGUAI. Lei no 2.53205. Que establece la zona de seguridad fronteriza de la República del Paraguay. Assunção, 17 fev. 2005. Disponível em: <https://www. catastro.gov.py/public/439bc5_ley\%20253205\%20seguridad\%20fronteriza. pdf>. Acesso em: 09 ago. 2018.

PAZ, Gabrielle S. Integração da América do Sul: o BNDES como agente da política regional do governo Lula. Anais do 1 Seminário Internacional de Ciência Política. Estado e democracia em mudança no século XXI, p. 1-21, 2015.

PORTO-GONÇALVES, Carlos Walter; QUENTAL, Pedro de Araújo. Colonialidade do poder e os desafios da integração regional na América Latina. Polis, 2012. Disponível em: <https://journals.openedition.org/polis/3749\#quotation>. Acesso em: 09 ago. 2018.

SENHORAS, Elói Martins. Regionalismo transnacional e integração física na América do Sul: um estudo geográfico sobre a Iniciativa de Integração da Infraestrutura Sul-Americana. Dissertação de Mestrado. Programa de Pós-Graduação em Geografia da Unicamp. Campinas: Unicamp, 2008, 232 p.

SENHORAS, E. M.; MOREIRA, F. A.; VITTE, C. C. S. "A Geografia da paradiplomacia subnacional na América do Sul”. Scripta Nova, vol. 12, 2008.

SILVA, Gutemberg V. A Cooperação Transfronteiriça entre Brasil e França: Ensaios e Expectativas neste século XXI. Tese de Doutorado. Programa de Pós-Graduação em Geografia da Universidade Federal do Rio de Janeiro. Rio de Janeiro: UFRJ, 2013.

TAVARES, Jeferson Cristiano. Eixos: novo paradigma do planejamento regional? Os eixos de infraestrutura nos PPA's nacionais, na IIRSA e na macrometrópole paulista. Cad. Metrop., São Paulo, v. 18, n. 37, pp. 671-695, set/dez 2016. 


\section{1}

UNASUL. Tratado Constitutivo da União de Nações Sul-Americanas. Brasília, 23 de maio de 2008. Disponível em: <http://www.itamaraty.gov.br/images/ed_integracao/docs_UNASUL/TRAT_CONST_PORT.pdf>. Acesso em: 09 ago. 2018.

ZIBECHI, Raúl. IIRSA: la integración a la medida de los mercados. Programa de las Américas. Silver City, NM: International Relations Center, 13 jun. 2006. 